\title{
The Research of Water Immersion Test of loess under overburden pressure
}

\author{
Zhang yu, Li hui a, Bao guibo, Jiang ningshan, Zhang wuyu, Yang xiaoyun \\ The Civil Engineering School Of Qinghai university, Qinghai, China; \\ ahuili_cug@hotmail.com
}

\begin{abstract}
Keywords: water immersion test; forecast; collapsibility;
Abstract. The collapsibility test in field can have several times to tens of times of error with computed results. The writer's purpose is to find the regulation of the develop of loess' collapsibility, a field test was completed, the writer also gave a formula to forecast the relationship between immersion time with collapse deformation of loess, which can fit the test well, may supply some calculation basis of engineering design and forecast in emergency situation.
\end{abstract}

\section{Introduction}

China made an index to describe the collapsibility, coefficient of collapsibility. When it is smaller than 0.015 , we called it loess non-collapsible under overburden pressure collapsible loess, as its weight cannot supply enough pressure, it will not cause collapse when water appeared, but when this coefficient is larger than 0.015 , of course, water will bring a huge collapse deformation and we called it loess collapsible under overburden pressure ${ }^{[1]}$. Loess can be Divided according to the emerge period into the Quaternary Early, middle and late Pleistocene and Holocene, which separate correspond to Q1、Q2、Q3 and Q4 loess. Its collapsibility has some difference due to it is not appeared in the same period, which make them go through a distinct time and bear different historical stress ${ }^{[2-4]}$.

The loess collapsible under overburden pressure is widely distributed in Qinghai province, it has typical large void ratio and water sensitivity, there have many foundations established on that special soil, its collapsibility may cause serious disaster ${ }^{[5-7]}$.

The research of collapsibility of loess start since the late 1950s,Sun Jian Zhong、Sun guan Zhong Guo Jian yang and Lin Zia Guan use the word 'collapsibility' in their article, they also command use the word to describe the phenomenon of volume change when loess under the dual-effect of pressure and water. These people primarily discussed the collapsibility's mechanism in cementation characteristics and porosity.

In general, there have two ways to measure the collapse deformation of loess, indoor test and field test, the indoor test is to acquire coefficient of collapsibility, it just test a piece of soil's collapsibility through using consolidation apparatus, on the one hand, it can be apparently to find that it can save much human and material resource, on the other hand, its results can be very inaccurate for follow reasons: this method not only does not consider the distribution characteristics of soil layer, but also does not consider the change of matric suction caused by seepage. When loess is soaked, their state is mostly in unsaturated ${ }^{[8-11]}$. With the development of unsaturated soil mechanics, people gradually realize that the matric suction is the main reason of unsaturated loess collapsibility ${ }^{[12-13]}$, thus, the calculated value compared to measured values tend to have a large error.

\section{Method and process of water immersion research}

The water immersion test is based on the on-site monitoring to obtain data, which can obtain vertical settlement and the surface subsidence range of test pit under immersion conditions, also, we try to test each horizon's settlement.

Steps are as follows: 
1.Foundation pit excavation, use excavators and earth moving vehicles combined operation, excavation radius is $10 \mathrm{~m}$, foundation pit's depth is $0.5 \mathrm{~m}$.

2.Take the line, using steel tape to determine the site of deep punctuation.

3. Use the rig to drill a hole at the determined deep punctuation in preset depth.

4.Hire labor to dig shallow punctuation in the depth of $0.5 \mathrm{~m}$.

5.Make marks, deep punctuation material requires the same weight as the undisturbed soil that has been displaced. $\$ 20 \mathrm{~mm}$ Threading pipe has been adopted as Inner layer, $\$ 50 \mathrm{~mm}$ PVC pipe has been adopted as outer layer, they are connected by concrete block, a dividing rule with accuracy of $0.001 \mathrm{~m}$ is fixed on the threading pipe to measure the collapsibility, the purpose of using PVC pipe is to decrease the friction with the contact of soil and can make threading pipe free loop.

6 . Bury the deep and shallow marks separately, then pave sand and gravel with $10 \mathrm{~cm}$ to make the water infiltrate equably.

7.Observe and record the readings of deep and shallow marks continuously, when the data is at a stable level, adopt that as an initial reading. After that, start water injection and keep water table at $30 \mathrm{~cm}-40 \mathrm{~cm}$. To make every day's water consumption clear, we equipped with water meter with accuracy of $0.1 \mathrm{~m}^{3}$ and record mark's settlement through the change of dividing rule and datum point reading.

8. When the average settlement of the last 5 days is less than $1 \mathrm{~mm} / \mathrm{d}$, the water injection stops

9.After the water injection stopped, keep record the settlement of the deep and shallow marks reading. When the average settlement of the last 5 days was less than $1 \mathrm{~mm} / \mathrm{d}$, the experiment was finished.

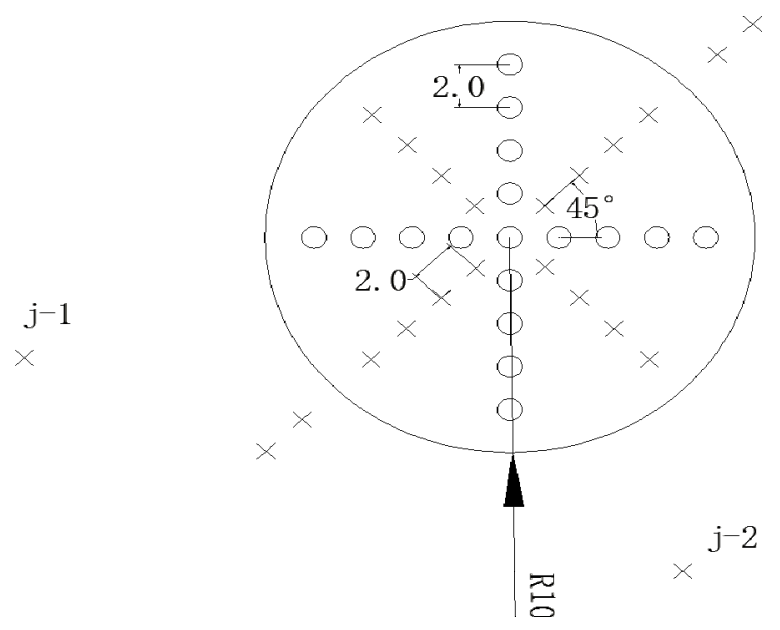

Figure1 Arrangement of marks

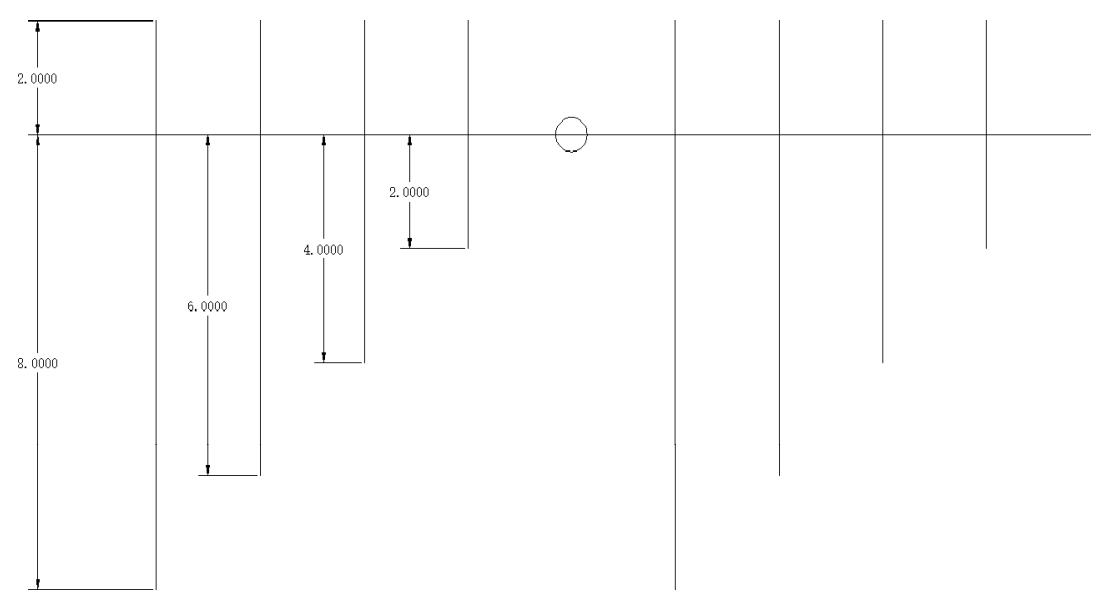

Figure2 Profile of the pit(deep mark) 
Through the data that get from every day's monitor, finally the relationship between water immersion time and accumulated collapse deformation has been acquired and the center point's data has been showed in the follow picture.

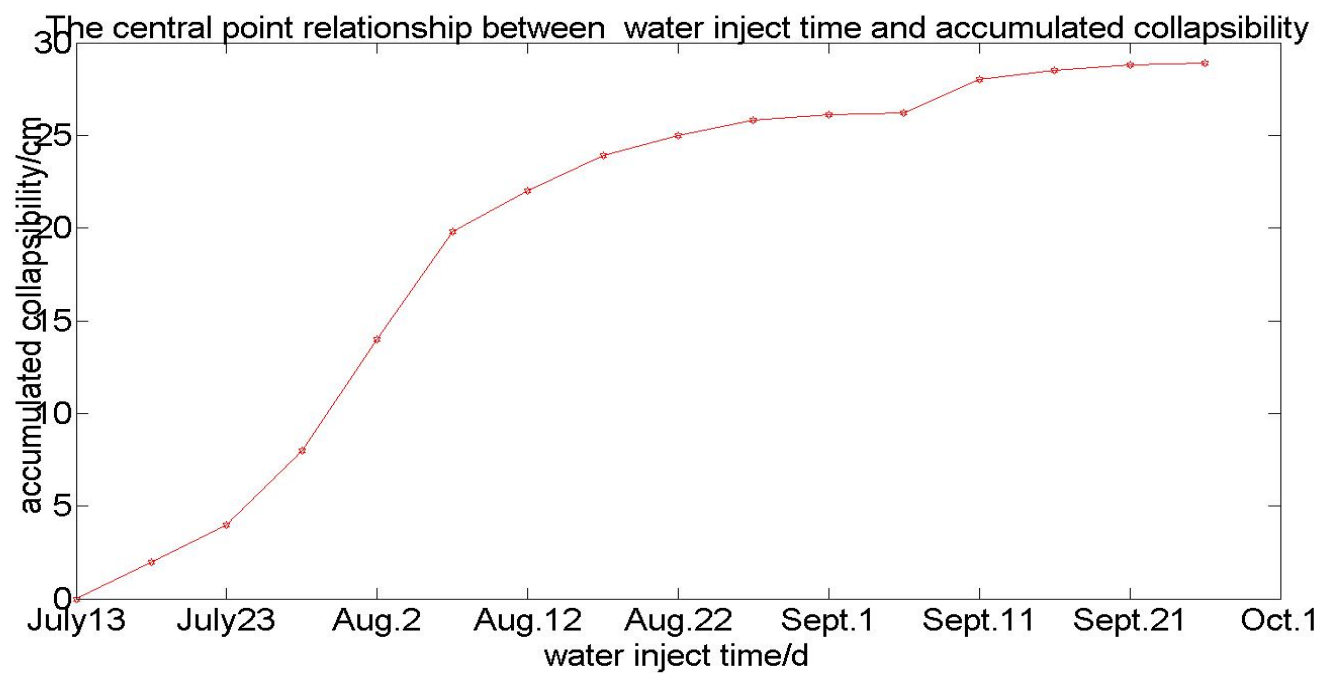

Figure 3 relationship between inject time and collapse deformation

The time begin to generate collapse deformation is at the beginning of 4 days and it cost 72 days to finish this test, which means if we do not handle the water that saved on loess foundation in 3 days, there might happened an uneven settlement. At the initial collapse deformation time, it develops slowly because the water have not cross all the soil, as the time goes by, that proceed need 4-7days according to references ${ }^{[14-15]}$, loess have enough water and pressure, the water content is increase continuous and that caused the matric suction decrease, in the other words, the soil's ability to hold water decrease in a quick time, the loess' structure get damaged by the water and pressure's dual functions, at this stage, collapse deformation develop very quickly. In the third stage, the speed of collapse deformation become more stable and most deformation has completed in the last stage, keep water inject until there has no change in record, the criterion of 'no change' is the average of last 5 day's collapse deformation are less than $1 \mathrm{~mm} / \mathrm{d}$. When there has no water immersion in the pit, the collapse deformation appears again, it accounted almost 9 percent of general deformation, that is because the increase of the matric suction makes the loess get further damaged. The center points of pit have the largest deformation, the final collapse deformation was $0.283 \mathrm{~m}$. overall, with the increase of time, the variation characters of the development of collapse deformation is slow-fast-slow.

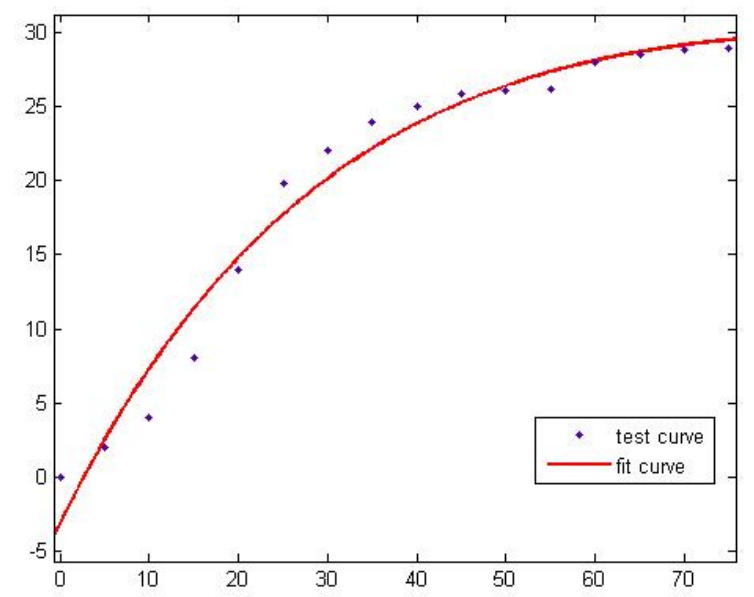

Figure4 fit curve contract with test curve 
And the writer gives a fit formula to simulate the testing data to forecast the collapse deformation

$$
\mathrm{f}(\mathrm{x})=40.59 * e^{-0.00234 t}-43.65 * e^{-0.03 \mathrm{t}}
$$

The R-square is 0.9704 , we can see the fitting is not bad and it has some function in forecast.

\section{Conclusions}

(1) The water immersion test shows that the loess collapse deformation' develop has the character of slow-fast-slow, which have some function in forecast loess' collapsibility.

(2) The formula $\mathrm{f}(\mathrm{x})=40.59 * e^{-0.00234 t}-43.65 * e^{-0.03 \mathrm{t}}$ can describe the relationship between collapse deformation with water immersion time well, may supply some calculation basis of engineering design and forecast in emergency.

\section{Acknowledgements}

The author appreciates the support of four research projects, The Natural Science Foundation of Qinghai province(2016-ZJ-766), the National Natural Science Foundation of China (Grants No. 51768060), The Natural Science Foundation of Qinghai province(2015-ZJ-722) and the Cooperation Program of Qinghai Province (Grants No.2017-HZ-804)

\section{References}

[1] GB50025-2004 Code for building construction in collapsible loess regions[S].Beijing: China Architecture and Building Press,2004. (in Chinese)

[2] Chen Zhenghan. On basic theories of unsaturated soils and special soils[A]. Chinese Journal of Geotechnical Engineering,2014, Vol36:202-272. (in Chinese)

[3] Chen Chingliu. True triaxial tests on structural effects on strength of intact loess[A].Chinese Journal of Geotechnical Engineering,2013,VOL35,No12: 2323-2327. (in Chinese)

[4] Hu Zaiqiang, SHEN Zhujiang, XIE Dingyi. Research on structural behavior of unsaturated loess[J]. Chinese Journal of Rock Mechanics and Engineering, 2000,19(6): 775-779 (in Chinese)

[5] Xie DY. Exploration of some new tendencies of in research of loess soil mechanics[J]. Chinese Journal of Geotechnical Engineering,2001,Vol3(1) :3-13.(in Chinese)

[6] Li Zhe.Non-uniform settlement of large-scale building on collapsible loess ground and its treatment strategy[A]Journal Of Natural Disaster,2003,Vol12(4):170-173. (in Chinese)

[7] Shao Shengjun, Collapse deformation evaluation method of loess tunnel foundation[A]Chinese Journal of Rock Mechanics and Engineering.2017Vol,36(5):1290-1300. (in Chinese)

[8] Barden L, et al. Volume change characteristics of unsaturated clay[J]. Soil Mech.Found.Div. 1969, Vol 95, SM1,33-52.

[9] Yao Zhihua, Chen Zhenghan, Huang Xuefeng, et al. Hydraulic conductivity of unsaturated undisturbed and remolded Q3 loess[J]. Chinese Journal of Geotechnical Engineering, 2012, Vol34(6): 1020-1027. (in Chinese)

[10] Miller, C. J., Yesiller, N., Yaldo, K. and Merayyan, S. Impact of soil type and compaction conditions on soilwater characteristic. 2002. 128(9):722-742.

[11] Miller, G. A., Khoury, C. N., Muraleetharan, K. K., Liu,C. Y. and Kibbey, T. C. G. 2008. Effects of soils skeleton deformations on hysteretic soil water characteristic curves: Experiments and simulations. Water Resource. Res. 44: W00C06, doi: 10.1029/2007WR006492.

[12] Xu Ling. Discussion on the mechanism of loess collapsibility from the perspective of unsaturated soil 
mechanics[A]. Theory Hydrogeology \& Engineering Geology,2009,Vol04:62-65.(in Chinese)

[13] Xing Yichuan. Effective stress and collapse process of unsaturated loess[A]. Chinese Journal of Rock Mechanics and Engineering,2004, Vol:23:1100-1103. (in Chinese)

[14] Huang Xuefeng. Study on foundation treatment thickness and treatment method for collapse loess with large thickness[J]. Chinese Journal of Rock Mechanics and Engineering,2007,26(Supp.2): 4332-4338.(in Chinese)

[15] Yang Xiaohui. Experimental study on collapsibility evaluation and treatment depths of collapsible loess upon self-weight with thick depth[A]. Chinese Journal of Rock Mechanics and Engineering,2014, Vol33:1064-1074. (in Chinese) 